\title{
Iron(III)-Mediated AGET ATRP of Methyl Methacrylate in the Absence of Additional Ligand
}

\author{
Svetlana A. Bulgakova*, Evgeniya S. Volgutova, Irina E. Khokhlova \\ Research Institute of Chemistry, University of Nizhny Novgorod, Nizhny Novgorod, Russia \\ Email: *sbulg@ichem.unn.ru, sbulg@mail.ru
}

Received June 3, 2012; revised July 1, 2012; accepted July 12, 2012

\begin{abstract}
The atom transfer radical polymerization on the mechanism of activator generation by electron transfer (AGET ATRP) of methyl methacrylate (MMA) in $N, N$-dimethylformamide (DMF) in the presence of the catalytic systems, namely, $\mathrm{CCl}_{4}-\mathrm{FeCl}_{3}$-1-acetyl-2-phenylhydrazine (APH) and $\mathrm{CCl}_{4}-\mathrm{FeCl}_{3}$-ascorbic acid (AA) is reported. The living feature of this process was confirmed by obtaining well-defined polymers with controlled molecular weight, narrow molecular weight distribution, and a chain-extension experiment. Both reducing agents, an APH as well as an AA, possess the equal kinetic activitis.
\end{abstract}

Keywords: Atom Transfer Radical Polymerization; Methyl Methacrylate; Iron; Ligand

\section{Introduction}

Atom transfer radical polymerization is acknowledged to be among the methods of controlled radical polymerization; it is a simple technique of well-defined polymers synthesis with predetermined molecular weights and a narrow molecular weight distribution (MWD) [1-5]. In comparison with other methods of controlled radical polymerization, ATRP has several advantages such as a broad spectrum of polymerizable monomers and available of initiators as well as the possibilities of the process performance over a wider temperature span and in the different solvents $[5,6]$.

ATRP is a recurring process of atom transfer between a macromolecular alkyl halide $\mathrm{P}_{\mathrm{n}}-\mathrm{X}$ and a redox-active complex of a transition metal $\mathrm{M}_{\mathrm{t}}^{\mathrm{n}}-\mathrm{X} /$ Ligand, in which the radicals $\mathrm{R} \cdot$ growth with the rate constant $k_{p}$ and are reversibly generated with the equilibrium constant $K=$ $k_{\text {act }} / k_{\text {deact }}$ (Scheme 1). Growing radicals can be also subject to a reaction of bimolecular termination with the rate constant $k_{t}$.

One of drawbacks of ATRP is the necessity of additional purification of the obtained polymer from a

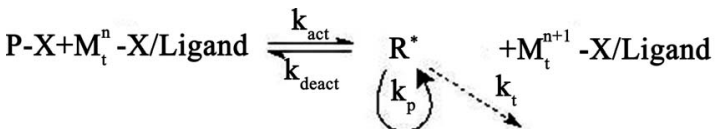

$$
\begin{aligned}
& \text { Monomer Bimolecular Termination }
\end{aligned}
$$

Scheme 1. Mechanism of ATRP. catalyst, namely, from a transition metal-ligand complex, which is used usually at concentrations from 0.1 to 1 mol\% in relation to the monomer. To diminish catalyst concentrations, the AGET ATRP method has been proposed in which an electron transfer activator is generated in situ [7-16]. For this purpose stoichiometrical amounts of a reducing agent are introduced into the system containing alkyl halide as an initiator, a monomer, and an oxidation-resistant deactivator $\left(\mathrm{M}^{\mathrm{n}+1}\right)$. After the $\left(\mathrm{M}^{\mathrm{n}}\right)$ activator generation, the kinetics of polymerization begins to resemble the kinetics of any ordinary ATRP process as illustrated in Scheme 2 on an example of $\mathrm{Cu}(\mathrm{II})$-mediated polymerization. Such reducing agents as tin(II)-2-ethylhexanoate $\left(\mathrm{Sn}(\mathrm{EH})_{2}\right)$, ascorbic acid; triethylamine, glucose are used in AGET ATRP.

In this work the MMA radical polymerization according to the AGET ATRP mechanism in the medium of dimethylformamide (DMF) with the participation of

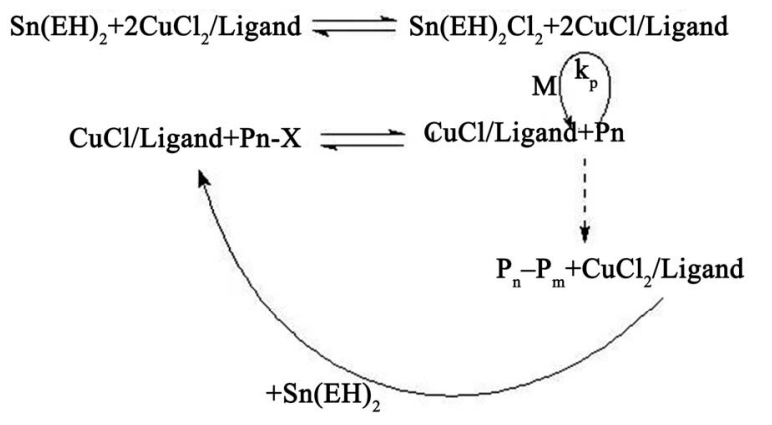

Scheme 2. Mechanism of complex $\mathrm{Cu}(\mathrm{I})$ generation in AGET ATRP.

"Corresponding author. 
$\mathrm{FeCl}_{3} \times 6 \mathrm{H}_{2} \mathrm{O}$, carbon tetrachloride $\left(\mathrm{CCl}_{4}\right)$ as an initiator, ascorbic acid (AA) and 1-acetyl-2-phenylhydrazine (APH) as the reducing agents have been used.

\section{Experimental Section}

\subsection{Chemicals}

First, MMA were dried over $\mathrm{CaH}_{2}$ and recondensated in vacuum. Iron chloride(III) in the form of crystalline hydrate $\mathrm{FeCl}_{3} \times 6 \mathrm{H}_{2} \mathrm{O}$ (high purity grade, Kupavnareaktiv), copper(II) chloride in the form of crystalline hydrate $\mathrm{CuCl}_{2} \times 2 \mathrm{H}_{2} \mathrm{O}$ (high purity grade, Kupavnareaktiv) and APH (Khimpolymer) were employed without additional purification. Ethanol, acetone, tetrahydrofuran (THF), DMF, $\mathrm{CCl}_{4}$ were purified via standard methods [17].

\subsection{Polymerization Procedure}

The polymerization of MMA was carried out in degassed end sealed ampoules. The PMMA samples were purified by the way of single re-precipitation from acetone into the mixture of ethanol and a $10 \%$ solution of oxalic acid (1:1) for removing of iron ions in conjunction with double re-precipitation of the samples from acetone into the mixture of ethanol:water $(1: 1)$; then the samples were dried in a vacuum up to the constant weight.

\subsection{Analysis}

The conversion of a monomer into a polymer was estimated gravimetrically. Molecular-mass characteristics of the polymers were estimated by gel permeation chromatography (GPC) in THF as an eluent at $40^{\circ} \mathrm{C}$ with a Shimadzu Prominence LC-20VP liquid chromatograph equipped with two columns (Styrogel $10^{6}$ and $10^{5} \AA$ ) and with a differential refractometer. Poly(methyl methacrylate) (PMMA) standards are used for calibration.

\subsection{Macroinitiator Synthesis}

PMMA-Cl macroinitiator was prepared by following similar procedures to that described above for ARGET ATRP with a ratio of MMA/2,2'-azobisisobutyronitrile (AIBN)/ $\mathrm{FeCl}_{3} / \mathrm{DMF}=623 / 1 / 2 / 286$ at $70^{\circ} \mathrm{C}$. The polymerization of MMA was carried out in degassed end sealed ampoules. The PMMA samples were purified by the way of single re-precipitation from acetone into the mixture of ethanol and a $10 \%$ solution of oxalic acid (1:1) with double re-precipitation of the samples from acetone into the mixture of ethanol: water (1:1); then the samples were dried in a vacuum up to the constant weight was reached and analyzed by GPC $\left(M_{n}=28500, M_{\mathrm{w}} / M_{n}=1.42\right.$ at $76 \%$ conversion $)$.

\subsection{Chain Extension of PMMA-CI Macroinitiator with MMA}

The post polymerization of MMA in the presence of the macroinitiator have been carried out with different catalytic systems, namely, PMMA-Cl/ $/ \mathrm{FeCl}_{3} / \mathrm{APH}$ in $46 \%$ (v/v) DMF, PMMA-Cl/ $/ \mathrm{FeCl}_{3} / \mathrm{AA}$ in $46 \%$ (v/v) DMF, PMMA-Cl/ $\mathrm{CuCl}_{2} /$ bipyridyne/APH in $10 \%$ (v/v) methanol. The PMMA samples were purified by the way of reprecipitation three times from acetone into the mixture of ethanol:water (1:1); then the samples were dried in a vacuum up to the constant weight was reached and analyzed by GPC.

\section{Results and Discussion}

We have shown previously that the radical polymerization of MMA in the presence of AIBN and $\mathrm{FeCl}_{3} \times 6 \mathrm{H}_{2} \mathrm{O}$ in DMF proceeds in the controlled regime without any complexing agent [18] likewise the radical polymerization of 2-etoxyethyl methacrylate and $t$-butyl methacrylate [19]. In all studied systems, the polymerization rate was first order with respect to monomer, the number-average molecular weight $\left(M_{n}\right)$ of polymers increased linearly with conversion, and polydispersity indexes were lower than 1.6. Further, it has been established [20] that introduction of APH into the catalytic system $\mathrm{AIBN}-\mathrm{FeCl}_{3}-$ DMF enables the synthesis of PMMA to be carried out in the controlled conditions at relatively low temperatures $\left(70^{\circ} \mathrm{C}\right)$ and at a higher rate in comparison with polymerization in the absence of APH. This phenomenon is due to the fact that APH fulfils the function of the generator of the lower oxidation state catalyst $\left(\mathrm{FeCl}_{2}\right)$ in situ .

Therein we have continued to study the effectiveness of the $\mathrm{FeCl}_{2} / \mathrm{DMF}$ catalyst and have investigated AGET ATRP of MMA. In this process an ATRP activator, $\left(\mathrm{Fe}^{2+}\right)$, is generated in situ by the interaction of a deactivator $\left(\mathrm{Fe}^{3+}\right)$ with a reducing agent. As an initiator, we used carbon tetrachloride which is widely studied in ATRP processes [21], and an ascorbic acid along with APH has been investigated, as a reducing agent.

In conformity with the AGET ATRP mechanism, the polymerization process should proceed in the following way:

$$
\begin{aligned}
& \mathrm{FeCl}_{3} / \mathrm{DMF}+\text { reducing agent } \leftrightarrow \mathrm{FeCl}_{2} / \mathrm{DMF} \\
& \mathrm{CCl}_{4}+\mathrm{FeCl}_{2} / \mathrm{DMF} \leftrightarrow \mathrm{CCl}_{3} \square+\mathrm{FeCl}_{3} / \mathrm{DMF} \\
& \mathrm{CCl}_{3} \square+\mathrm{M} \rightarrow \mathrm{CCl}_{3}-\mathrm{M} \square \\
& \mathrm{CCl}_{3}-\mathrm{M}+\mathrm{FeCl}_{3} / \mathrm{DMF} \leftrightarrow \mathrm{CCl}_{3}-\mathrm{M}-\mathrm{Cl}+\mathrm{FeCl}_{2} / \mathrm{DMF}
\end{aligned}
$$

Kinetic investigations show that MMA polymerization in the presence of the catalytic system $\mathrm{CCl}_{4} / \mathrm{FeCl}_{3} / \mathrm{DMF} /$ reducing agent proceeds, really, in accordance with this mechanism. At that, the nature of the reducing agent has no effect on the rate process: shown in Figure 1, both AA and APH have the same kinetic activity. A linear time-dependence of $\ln [M]_{0} /[M]_{t}$ (where $[M]_{0},[M]_{t}$ are the initial and current concentrations of MMA, respectively) indicates a constant concentration of propagating radicals 
and the controlled nature of the process. Furthermore, a linear increase in the number average molecular weights $M_{n}$ and the tendency to reduce the polydispersity with conversion, shown in Figure 2 confirm the MMA polymerization proceeds in a controlled fashion. It should be noted, however, that molecular weight values begin to increase for some values of $M_{n} \approx 7000$. This is probably due to the contribution of chain transfer reactions to carbon tetrachloride which accompany this process and violate the control reactions of chains termination in AGET ATRP of MMA.

Tables 1 and $\mathbf{2}$ demonstrate that increase in the concentrations of AA and APH leads neither to the polymerization rate changes nor to the changes of polymer molecular mass characteristics. At the same time it can be noted that the nature of a reducing agent does effect on the control of the MMA polymerization process. It is seen that the polymers obtained with the APH participation possess lower of polydispersity index in contrast to the samples synthesized in the presence of AA.

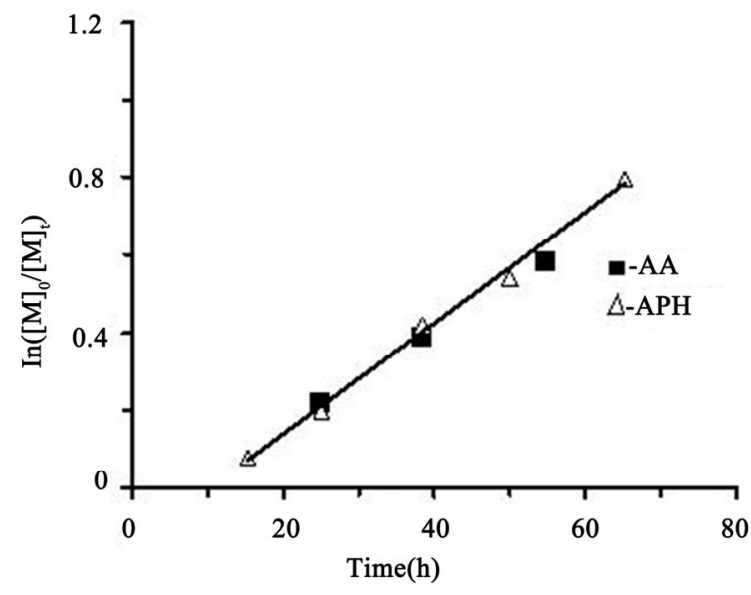

Figure 1. Kinetic plot of MMA conversion in the presence of $\mathrm{APH}$ and $\mathrm{AA}$ at the conditions: $\left[\mathrm{CCl}_{4}\right]_{0} /\left[\mathrm{FeCl}_{3}\right]_{0} /[$ reducing agent $]_{0}=2.5 / 1 / 1 ;\left[\mathrm{CCl}_{4}\right]_{0}=0.0311 \mathrm{M},[\mathrm{MMA}]_{0}=7.02 \mathrm{M}$, $70^{\circ} \mathrm{C}$.

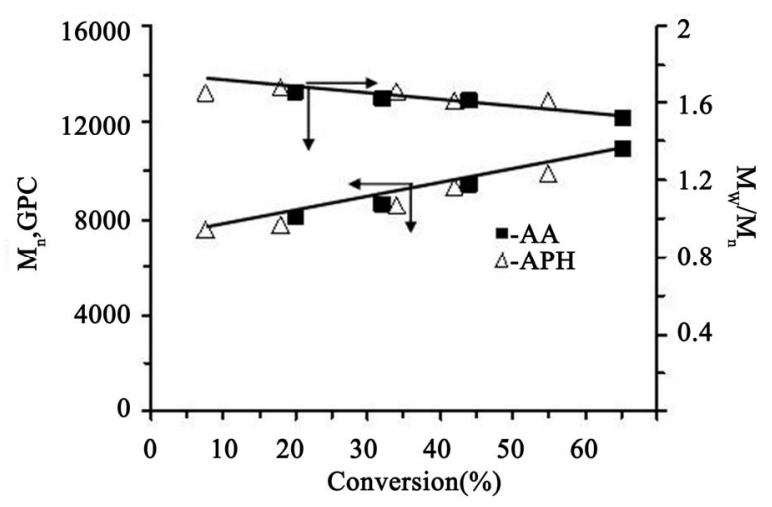

Figure 2. Dependence of $M_{n}$ and $M_{w} / M_{n}$ of PMMA on conversion in MMA polymerization in the presence of APH and AA. Under the same conditions as in Figure 1.
However, the results of Tables $\mathbf{1}$ and $\mathbf{2}$ were received with dissimilar initiator concentrations; because of it, it should be necessary to differentiate the influence of $\mathrm{CCl}_{4}$ as an initiator for more correct evaluation of reducing agent efficiency. As might be expected the polymerization rate and molecular weight of the polymer are initiator concentration dependent. Figure 3 shows, the rate of MMA polymerization increases monotonically with the $\mathrm{CCl}_{4}$ concentration irrespective of the reducing agent nature. The raise in initiator concentration is attended with a decrease of the molecular weight of the polymer in both systems (Tables 3 and 4) whereas the MWD remains unaltered, essentially; the exception is the system with the AA participation in which very high concentrations of $\mathrm{CCl}_{4}$ as an initiator lead to increase in $M_{w} / M_{\mathrm{n}}$ from 1.5 to 1.84 (Table 4).

Table 1. Influence of AA concentration on the molecular mass characteristics of PMMA prepared by AGET ATRP.

\begin{tabular}{ccccc}
\hline$\left[\mathrm{FeCl}_{3}\right]:[\mathrm{AK}]$ & Conversion (\%) & $M_{n \mathrm{GPC}} \times 10^{-3}$ & $M_{w \mathrm{GPC}} \times 10^{-3}$ & $M_{w} / M_{n}$ \\
\hline $1: 1$ & 94.5 & 3.6 & 6.7 & 1.84 \\
$1: 2$ & 96.0 & 3.8 & 7.0 & 1.84 \\
$1: 0.45$ & 95.5 & 3.7 & 6.7 & 1.82 \\
\hline
\end{tabular}

Polymerization conditions: $\left[\mathrm{CCl}_{4}\right]_{0} /\left[\mathrm{FeCl}_{3}\right]_{0} /[\mathrm{DMF}]_{0}=1 / 0.4 / 103,\left[\mathrm{CCl}_{4}\right]_{0}=$ $0.0311 \mathrm{M}, \mathrm{T}=70^{\circ} \mathrm{C}$, polymerization time $28.5 \mathrm{~h}$.

Table 2. Influence of APH concentration on the molecular mass characteristics of PMMA prepared by AGET ATRP.

\begin{tabular}{ccccc}
\hline$\left[\mathrm{FeCl}_{3}\right]:[\mathrm{APH}]$ & Conversion (\%) & $M_{n \mathrm{GPC}} \times 10^{-3}$ & $M_{w \mathrm{GPC}} \times 10^{-3}$ & $M_{w} / M_{n}$ \\
\hline $1: 1$ & 89.0 & 11.0 & 16.4 & 1.49 \\
$1: 2$ & 90.5 & 12.8 & 19.1 & 1.49 \\
$1: 0.45$ & 74.5 & 13.0 & 19.2 & 1.48 \\
\hline
\end{tabular}

Polymerization conditions: $\left[\mathrm{CCl}_{4}\right]_{0} /\left[\mathrm{FeCl}_{3}\right]_{0} /[\mathrm{DMF}]_{0}=1 / 0.4 / 103,\left[\mathrm{CCl}_{4}\right]_{0}=$ $0.0311 \mathrm{M}, \mathrm{T}=70^{\circ} \mathrm{C}$, polymerization time $93 \mathrm{~h}$.

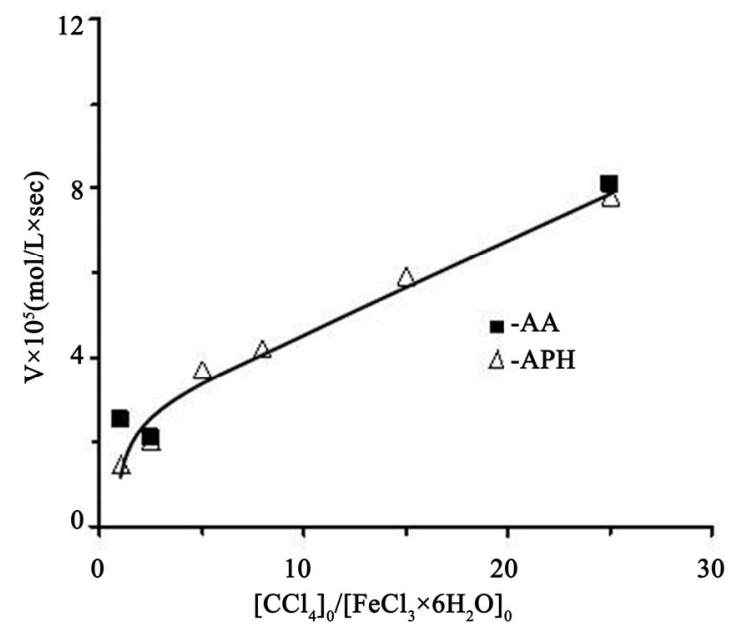

Figure 3. The effect of $\mathrm{CCl}_{4}$ concentrations on the MMA polymerization rate in the presence of $\mathrm{APH}$ and $\mathrm{AA}$; $\left[\mathrm{FeCl}_{3}\right]_{0}$ $=0.0124 \mathrm{M},[\mathrm{MMA}]_{0}=7.02 \mathrm{M},[\mathrm{AA}]_{0}=[\mathrm{APH}]_{0}=0.0124 \mathrm{M}$, ${ }_{70}^{\circ} \mathrm{C}$. 
Table 3. Results of MMA polymerization in the presence of $\mathrm{APH}$ at different concentrations of $\mathrm{CCl}_{4}$ as an initiator.

\begin{tabular}{cccccc}
\hline$\left[\mathrm{FeCl}_{3}\right]_{0} /\left[\mathrm{CCl}_{4}\right]_{0}$ & Conversion (\%) & $M_{n \mathrm{GPC}} \times 10^{-3}$ & $M_{w \mathrm{GPC}} \times 10^{-3}$ & $M_{w} / M_{n}$ & $\mathrm{~V} \times 10^{5}(\mathrm{~mol} / \mathrm{L} \times \mathrm{sec})$ \\
\hline $1: 25$ & 75 & 4.7 & 7.8 & 1.65 & 7.80 \\
$1: 15$ & 58 & 5.3 & 9.0 & 1.68 & 5.90 \\
$1: 8$ & 67 & 6.2 & 10.3 & 1.66 & 4.20 \\
$1: 5$ & 69 & 7.2 & 11.9 & 1.64 & 3.70 \\
$1: 2.5$ & 55 & 9.9 & 15.9 & 1.61 & 2.00 \\
$1: 1$ & 58 & 14.9 & 24.0 & 1.61 & 1.48 \\
\hline
\end{tabular}

Polymerization conditions: $\left[\mathrm{FeCl}_{3}\right]_{0}=[\mathrm{APH}]_{0}=0.0124 \mathrm{M} ;[\mathrm{MMA}]_{0}=7.02 \mathrm{M} ; 70^{\circ} \mathrm{C}$.

Table 4. Results of MMA polymerization in the presence of $\mathrm{AA}$ at different concentrations of $\mathrm{CCl}_{4}$ as an initiator.

\begin{tabular}{cccccc}
\hline$\left[\mathrm{FeCl}_{3}\right]_{0} /\left[\mathrm{CCl}_{4}\right]_{0}$ & Conversion $(\%)$ & $M_{n \mathrm{GPC}} \times 10^{-3}$ & $M_{w} \times 10^{-3}$ & $M_{w} / M_{n}$ & $\mathrm{~V} \times 10^{5}(\mathrm{~mol} / \mathrm{L} \times \mathrm{sec})$ \\
\hline $1: 25$ & 95 & 3.6 & 6.7 & 1.84 & 8.1 \\
$1: 2.5$ & 65 & 10.9 & 16.5 & 1.52 & 2.1 \\
$1: 1$ & 73 & 16.1 & 24.6 & 1.53 & 2.5 \\
\hline
\end{tabular}

Polymerization conditions: $\left[\mathrm{FeCl}_{3}\right]_{0}=[\mathrm{AA}]_{0}=0.0124 \mathrm{M} ;[\mathrm{MMA}]_{0}=7.02 \mathrm{M} ; 70^{\circ} \mathrm{C}$.

The proposed system for the activator generation in situ was effective also and when we used instead of $\mathrm{CCl}_{4}$ the PMMA-Cl macroinitiator which was synthesized using the $\mathrm{AIBN} / \mathrm{FeCl}_{3} / \mathrm{DMF}$ catalytic system. As shown in Figure 4, at the MMA polymerization in the presence of a PMMA-Cl/ $\mathrm{FeCl}_{3} / \mathrm{APH}$ catalyst system at conversion of $28.5 \%$ the polymer chain has elongated by 1.6 times without any changes of polydispersity. In cases with a PMMA$\mathrm{Cl} / \mathrm{FeCl}_{3} / \mathrm{AA}$ catalyst system at conversion of $22 \%$, the polymer chain has become 1.9 times as long and polydispersity has remained unchanged, too.

These results demonstrate that the AA reducing agent elongates a chain slightly more effectively in comparison with APH. However, better results of MMA post polymerization in the presence of the same macroinitiator have been obtained with another catalytic system, namely, $\mathrm{CuCl}_{2} \times 2 \mathrm{H}_{2} \mathrm{O} /$ bipyridyne/APH the length of a polymer chain increased 1.4 times at the conversion of $4 \%$ and 2.2 times at $6 \%$ conversion and, furthermore, a polydispersity of PMMA decreased from 1.42 to 1.18 (Figure 5).

\section{Conclusions}

New evidence were obtained that the $\mathrm{FeCl}_{3} / \mathrm{DMF}$ system is a metal complex catalyst and it acts not only in Reverse ATRP with AIBN radical initiator but in AGET ATRP of MMA which proceeds in the presence of a $\mathrm{CCl}_{4}$ initiator and $\mathrm{APH}$ and $\mathrm{AA}$ as reducing agents. The $\mathrm{CCl}_{4} / \mathrm{FeCl}_{3} / \mathrm{DMF} / \mathrm{APH}$ and $\mathrm{CCl}_{4} / \mathrm{FeCl}_{3} / \mathrm{DMF} / \mathrm{AA}$ systems enable to carry out the PMMA synthesis in the controlled fashion according to the AGET ATRP mechanism as demonstrated by the first order of reaction with respect to the monomer concentration, linear growth of molecular weight, and decrease in polydispersity index of polymer with conversion as well as conducting of a chainextension reaction. The concentration of the reducing agent

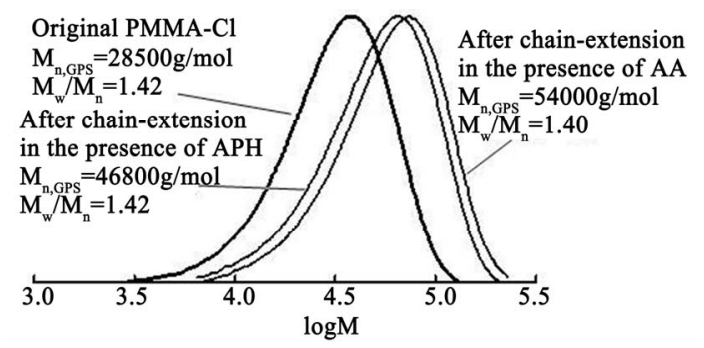

Figure 4. GPC curves before and after chain extension with PMMA as macroinitiator. Original PMMA prepared via Reverse ATRP in the presence of $\mathrm{AIBN} / \mathrm{FeCl}_{3} / \mathrm{DMF}$ catalytic system. Chain extended polymerization conditions: [PMMA$\mathrm{Cl}]_{0}=5 \times 10^{-3} \mathrm{M},\left[\mathrm{FeCl}_{3}\right]_{0}=5 \times \mathbf{1 0}^{-3} \mathrm{M},[\mathrm{APH}]_{0}=[\mathrm{AA}]_{0}=5$ $\times 10^{-3} \mathrm{M}$ in $46 \%(\mathrm{v} / \mathrm{v}) \mathrm{DMF}$, time $=189 \mathrm{~h}$, conversion $=$ $\mathbf{2 8 . 5 \%}$ in the presence of $\mathrm{APH}$, and time $=209 \mathrm{~h}$, conversion $=22 \%$ in the presence of $\mathrm{AA} ; \mathrm{T}=70^{\circ} \mathrm{C}$.

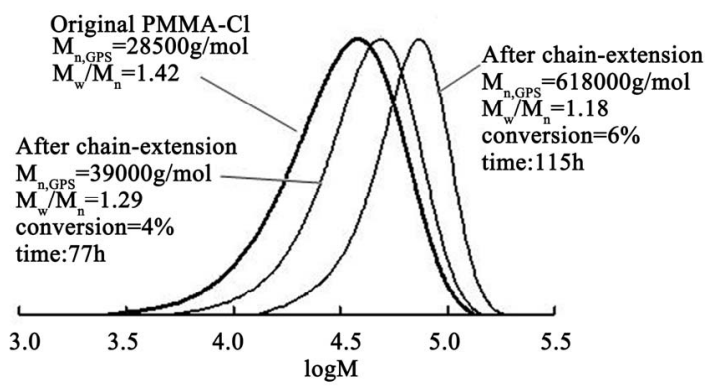

Figure 5. GPC curves before and after chain extension with PMMA as macroinitiator. Original PMMA prepared via Reverse ATRP in the presence of $\mathrm{AIBN} / \mathrm{FeCl}_{3} / \mathrm{DMF}$ catalytic system. Chain extended polymerization conditions: [PMMA $]_{0}$ $=5 \times 10^{-3} \mathrm{M},\left[\mathrm{CuCl}_{2} \times 2 \mathrm{H}_{2} \mathrm{O}\right]_{0}=5 \times 10^{-3} \mathrm{M},[\mathrm{APH}]_{0}=5 \times$ $10^{-3} \mathrm{M}$, [Bipyridyne $]_{0}=2 \times 10^{-2} \mathrm{M}$ in $10 \%(\mathrm{v} / \mathrm{v})$ methanol, $\mathrm{T}$ $=70^{\circ} \mathrm{C}$.

has no effect on the rate of AGET ATRP and molecular weight characteristics of PMMA. Increase in concentration of $\mathrm{CCl}_{4}$ as an initiator, both in the system with APH 
and with AA, results in decrease in polymer molecular weight and rise in the rate of polymerization. Molecular weight distribution of PMMA obtained with APH does not depend on the concentration of $\mathrm{CCl}_{4}$, while in the system with AA 25-fold increase in initiator concentration with respect to the $\mathrm{FeCl}_{3}$, leads to an increase of the polydispersity index from 1.5 to 1.8 .

A chain-extension reaction of PMMA-Cl macroinitiator was carried out in the presence of $\mathrm{FeCl}_{3} / \mathrm{MMA} / \mathrm{re}$ ducing agent and $\mathrm{CuCl}_{2} / \mathrm{Bipyridyne} / \mathrm{APH}$. Original macroinitiator with the terminal chlorine atom was obtained by Reverse ATRP in the presence of $\mathrm{FeCl}_{3} / \mathrm{AIBN} / \mathrm{DMF}$ catalytical system. It turned out that $\mathrm{AA}$, as a reducing agent, is more effective than APH in terms of the polymer chain-extension, at the same time, the $\mathrm{CuCl}_{2}$ /Bipyridyne complex is more active, noticeably, than $\mathrm{FeCl}_{3} / \mathrm{DMF}$ catalyst in AGET ATRP with participation of PMMA-Cl macroinitiator.

\section{Acknowledgements}

The work was supported by the Analytical Federal Target Program Development of the Scientific Potential of Higher Education (2009-2012), project no. 2.1.1/12613.

\section{REFERENCES}

[1] M. Kato, M. Kamigaito, M. Sawamoto and T. Higashimura, "Polymerization of Methyl Methacrylate with the Carbon Tetrachloride/Dichlorotris-(Triphenyl-phosphine) Respectfully Yours, Uthenium(II)/Methylaluminum Bis(2,6ditert-butylphenoxide) Initiating System: Possibility of Living Radical Polymerization," Macromolecules, Vol. 28, No. 5, 1995, pp. 1721-1723. doi:10.1021/ma00109a056

[2] J. S. Wang and K. Matyjaszewski, "Controlled/'Living' Radical Polymerization. Halogen Atom Transfer Radical Polymerization Promoted by a $\mathrm{Cu}(\mathrm{I}) / \mathrm{Cu}$ (II) Redox Process," Macromolecules, Vol. 28, No. 23, 1995, pp. 79017910. doi:10.1021/ma00127a042

[3] V. Percec and B. Narboiu, “'Living' Radical Polymerization of Styrene Initiated by Arenesulfonyl Chlorides and CuI(bpy) $)_{\mathrm{n}}$," Macromolecules, Vol. 28, No. 23, 1995, pp. 7970-7972. doi:10.1021/ma00127a057

[4] M. Kamigaito, T. Ando and M. Sawamoto, "Metal-Catalyzed Living Radical Polymerization," Chemical Reviews, Vol. 101, No. 12, 2001, pp. 3689-3746. doi:10.1021/cr9901182

[5] K. Matyjaszewski and J. H. Xia, "Atom Transfer Radical Polymerization," Chemical Reviews, Vol. 101, No. 9, 2001, pp. 2921-2990. doi:10.1021/cr940534g

[6] J. Qiu, B. Charleux and K. Matyjaszewski, "Controlled/ Living Radical Polymerization in Aqueous Media: Homogeneous and Heterogeneous Systems," Progress in Polymer Science, Vol. 26, No. 10, 2001, pp. 2083-2134. doi:10.1016/S0079-6700(01)00033-8

[7] W. Jakubowski and K. Matyjaszewski, “Activator Generated by Electron Transfer for Atom Transfer Radical Po- lymerization," Macromolecules, Vol. 38, No. 10, 2005, pp. 4139-4146. doi:10.1021/ma0473891

[8] K. Min, H. F. Gao and K. Matyjaszewski, "Development of an ab Initio Emulsion Atom Transfer Radical Polymerization: From Microemulsion to Emulsion," Journal of the American Chemical Society, Vol. 128, No. 32, 2006, pp. 10521-10526. doi:10.1021/ja0629054

[9] D. X. Wu, Y. F. Yang, X. H. Cheng, L. Liu, J. Tian and H. Y. Zhao, "Mixed Molecular Brushes with PLLA and PS Side Chains Prepared by AGET ATRP and Ring-Opening Polymerization," Macromolecules, Vol. 39, No. 22, 2006, pp. 7513-7519. doi:10.1021/ma061141+

[10] P. Kwiatkowski, J. Jurczak, J. Pietrasik, W. Jakubowski, L. Mueller and K. Matyjaszewski, "High Molecular Weight Polymethacrylates by AGET ATRP under High Pressure," Macromolecules, Vol. 41, No. 4, 2008, pp. 10671069. doi: $10.1021 / \mathrm{ma} 702770 \mathrm{u}$

[11] J. K. Oh, H. C. Dong, R. Zhang, K. Matyjaszewski and H. Schlaad, "Preparation of Nanoparticles of Double-Hydrophilic PEO-PHEMA Block Copolymers by AGET ATRP in Inverse Miniemulsion," Journal of Polymer Science Part A: Polymer Chemistry, Vol. 45, No. 21, 2007, pp. 4764-4772. doi:10.1002/pola. 22230

[12] K. Min, W. Jakubowski and K. Matyjaszewski, "AGET ATRP in the Presence of Air in Miniemulsion and in Bulk," Macromolecular Rapid Communications, Vol. 27, No. 8, 2006, pp. 594-598. doi:10.1002/marc.200600060

[13] L. Zhang, Z. P. Cheng, S. P. Shi, Q. H. Li and X. L. Zhu, "AGET ATRP of Methyl Methacrylate Catalyzed by $\mathrm{FeCl}_{3}$ /Iminodiacetic Acid in the Presence of Air," Polymer, Vol. 49, No. 13-14, 2008, pp. 3054-3059. doi:10.1016/j.polymer.2008.04.057

[14] L. Zhang, Z. Cheng, F. Tang, Q. Li and X. Zhu, "Iron(III)-Mediated ATRP of Methyl Methacrylate Using Activators Generated by Electron Transfer," Macromolecular Chemistry and Physics, Vol. 209, No. 16, 2008, pp. 1705-1713. doi:10.1002/macp.200800109

[15] R. Luo and A. Sen, "Electron-Transfer-Induced IronBased Atom Transfer Radical Polymerization of Styrene Derivatives and Copolymerization of Styrene and Methyl Methacrylate," Macromolecules, Vol. 41, No. 12, 2008, pp. 4514-4518.

[16] G. Hizal, U. Tunca, S. Aras and H. Mert, "Air-Stable and Recoverable Catalyst for Copper-Catalyzed Controlled/ Living Radical Polymerization of Styrene; In Situ Generation of $\mathrm{Cu}(\mathrm{I})$ Species via Electron Transfer Reaction," Journal of Polymer Science Part A: Polymer Chemistry, Vol. 44, No. 1, 2006, pp. 77-87. doi:10.1002/pola.21048

[17] A. Weissberger, E. S. Proskauer, J. A. Riddick and E. E. Toops, "Organic Solvents: Physical Properties and Methods of Purification," Wiley, New York, 1955.

[18] S. Bulgakova, E. Tumakova and Yu. Semchikov, "Controlled Polymerization of Methyl Methacrylate in the Presence of an $\mathrm{FeCl}_{3}$-Complexing Agent System," Polymer Science Series B (Russia), Vol. 51, No. 9-10, 2009, pp. 389-394. doi:10.1134/S1560090409090103

[19] S. A. Bulgakova, E. S. Tumakova, A. V. Zhizhikina, S. D. Zaitsev, L. V. Kurushina and Y. D. Semchikov, "Controlled Radical Polymerization of Methacrylates of Vari- 
ous Structures in the Presence of the AIBN-FeCl $3-N, N$ Dimethyl-formamide Catalytic System," Polymer Science Series B (Russia) Vol. 53, No. 1-2, 2011, pp. 57-63. doi:10.1134/S1560090411020011

[20] S. A. Bulgakova, E. S. Volgutova, E. A. Kiseleva, I. E. Khokhlova and Y. D. Semchikov, "Controlled Radical Polymerization of Methyl Methacrylate in the Presence of Azobisisobutyronitrile, Iron(III) Chloride, and the Reduc- ing Agent 1-Acetyl-2-phenylhydrazine in Dimethylformamide," Polymer Science Series B (Russia), Vol. 53, No. 11-12, 2011, pp. 563-567. doi:10.1134/S1560090411110017

[21] T. Ando, M. Kamigaito and M. Sawamoto, "Iron(II) Chloride Complex for Living Radical Polymerization of Methyl Methacrylate," Macromolecules, Vol. 30, No. 16, 1997, pp. 4507-4510. doi:10.1021/ma961478j. 